\title{
Latin-American guidelines for opioid use in chronic nononcologic pain
}

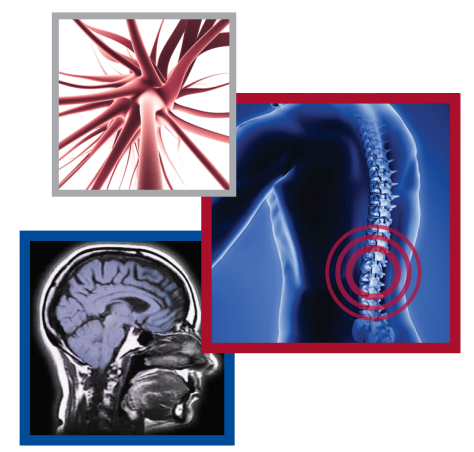

\begin{abstract}
Argelia Lara-Solares ${ }^{*}$, , Carlos Aguayo Zamora², César Amescua García ${ }^{3}$, João Batista Santos Garcia ${ }^{4}$, María del Rosario Berenguel Cook ${ }^{5}$, Patricia Bonilla Sierra6 ${ }^{6}$ Durval Campos Kraychete ${ }^{7}$, José Alberto Flores Cantisani ${ }^{8}$, Carlos Guerrero ${ }^{9}$, María del Rocío Guillén Núñez ${ }^{10}$, John Jairo Hernández Castro ${ }^{11}$, Andrés Hernández Ortíz" Aziza Jreige Iskandar ${ }^{12}$, Osvandré Lech ${ }^{13}$, Jacqueline Macías Guerra ${ }^{14}$, Gerardo Ramírez Samayoa ${ }^{15}$, Edwin Rangel Morillo ${ }^{16}$, María Antonieta Rico Pazos ${ }^{17}$ \& Manuel Sempértegui Gallegos ${ }^{18}$
\end{abstract}

\section{Practice points}

\section{Current issues}

- Pain is a major public health concern worldwide.

- In Latin America the situation is compounded by the low use of opioid-based medicines as a result of physician 'opiophobia'.

- Optimal pain relief requires access to a range of analgesics, including opioid drugs for moderate to severe pain.

- The physician must consider a range of factors including efficacy, safety and adherence, and the risk of abuse/addiction, to achieve the greatest benefit.

\section{Future perspective}

- Key opinion leaders from Latin America have recommended changes to current guidelines so as to optimize the use of opioid analgesics in chronic nononcologic pain to improve pain relief and patients' quality of life.

\footnotetext{
'Instituto Nacional de Ciencias Médicas y Nutrición 'Salvador Zubirán', Mexico City, Mexico ${ }^{2}$ Hospital Clinico FUSAT, Rancagua, Chile

${ }^{3}$ Hospital Ángeles, Tijuana, Mexico

${ }^{4}$ Pain \& Palliative Care, Federal University of Maranhao, Brazil

${ }^{5}$ Totalcare-Oncosalud-Lima, Perú

${ }^{6}$ Instituto Oncológico 'Luis Razetti', Pain clinic \& Palliative Care, Instituto Médico La Floresta, Caracas, Venezuela ${ }^{7}$ Federal University of Bahia, Coordinator of the Pain Outpatient Clinic, Brazilian Society for the Study of Pain, Brazil

${ }^{8}$ Programa Regional de Cuidados Paliativos, Unidad Médica de Alta Especialidad No. 25, IMSS, Monterrey NL, Mexico

${ }^{9}$ Hospital Universitario Fundación Santa Fe, Bogotá. Universidad de los Andes, Colombia

${ }^{10}$ Medicina del Dolor y Cuidados Paliativos, Hospital Médica Sur, Mexico City, Mexico

"Pain Medicine \& Palliative Care, Universidad del Rosario - MEDERI, Bogotá, Colombia

${ }^{12}$ Rehabilitation Residency Program, UCV, Unidad de Rehabilitación DM, Maracay, Venezuela

${ }^{13}$ Orthopaedic Residency Program, UFFS-HSVP-IOT, Passo Fundo, Brazil

${ }^{14}$ Hospital 'Luis Vernaza', Universidad Católica Santiago de Guayaquil, Guayaquil, Ecuador

${ }^{15}$ Hospital General San Juan de Dios, Universidad de San Carlos de Guatemala, HUMANA, Centro de Tratamiento e Investigación de

Epilepsia en Guatemala

${ }^{16}$ Physical Medicine \& Rehabilitation, Panama

${ }^{17}$ Clínica Alemana, Universidad del Desarrollo, Santiago, Chile

${ }^{18}$ Pain Clinic, Hospital Metropolitano, Quito, Ecuador

*Author for correspondence: Tel.: +52 (55) 5487 0900, ext. 5011; argelia.lara@dolorypaliativos.org
}

Future iss 


\section{KEYWORDS}

- analgesics • guidelines

- Latin America - opioids

- pain

Aim: Latin-American experts in the use of opioids in patients with chronic nononcologic pain (CNOP) have updated existing recommendations to current Latin-American reality. Methods: Several key opinion leaders from Latin America participated in a face-to-face meeting in Guatemala (April 2015) to discuss the use of opioids in CNOP. Subgroups of experts worked on specific topics, reviewed the literature and shaped the final manuscript. Results: The expert panel developed guidelines taking into consideration the utility of both opioid and nonopioid analgesics and factors pertaining to their efficacy, safety, adherence, administration and risks for abuse/addiction. Conclusion: Latin-American guidelines for the use of opioids in CNOP should improve pain relief and patients' quality of life by increasing access to these effective agents.

First draft submitted: 20 December 2016; Accepted for publication: 23 January 2017; Published online: 7 February 2017

Pain is an important public health issue worldwide. The Montreal Canada Declaration (2010) - supported by International Association for the Study of Pain, European Pain Federation and WHO - claims that access to pain management is a fundamental human right, and that every person in pain should be adequately assessed and receive an effective treatment without discrimination [1]. The right treatment for pain depends on several factors, such as accessibility and availability of analgesics, especially opioids because of their wide range of efficacy; but this does not always happen [2].

The International Association for the Study of Pain defines chronic pain as "persistent or recurrent pain that lasts for more than three months" [3]. Prevalence around the world ranges from 1 to $60 \%$ and pain has a great economic impact. Public expenditure reaches nearly 3\% of the European gross domestic product; that is to say, it costs more than heart diseases and cancer combined [4]. Nevertheless, the scope of the problem in Latin America is not clear; available data are scarce and vary among the different countries. Thus, there is a clear need for epidemiologic studies in that region [5]. As a common cause of long-term disability in middle-aged patients $(12.5 \%)$ chronic pain is an important medical issue, with a serious, socio-economic impact [6].

The majority of Latin-American countries have national programs to ensure the availability of controlled drugs for pain relief [7]. Nevertheless, most initiatives appear to deter the use of these agents; hence, the availability and use of opioid analgesics remains very low in many countries. This is highlighted in worldwide consumption data which show that in developed countries people consume about $79 \%$ of global morphine, whereas in developing countries (which reaches $80 \%$ of the world population) the percentage is only $6 \%[8]$.

Latin-American patients suffer from pain for many reasons, but they are not properly treated because of, along with other causes, physicians' 'opiophobia'. The latter cause is due to inaccurate assumptions regarding the treatment of chronic nononcologic pain (CNOP), the health professionals fear of misuse and addiction, as well as a wrong perception of a lack of efficacy of opioids [9].

A panel of experts (The Change Pain Latin America, CPLA) gathered in Guatemala City (17-18th April 2015) to discuss and develop general recommendations for the use of opioids in CNOP in Latin America, based on best available evidence. The objectives of the guidelines presented herein are to update the understanding and knowledge of Latin-American physicians and to develop a clinical tool for use at every level of medical care.

\section{Patient selection}

Which patients with CNOP are candidates for opioid treatment and which patients are not? (Box 1).

Is it possible to provide relief to the patient if nonopioid analgesics, interventionist treatments and nonpharmacologic therapies have failed? If so, what are the risks? The answers to these questions call for a good level of understanding based on appropriate clinical experience.

Kalso et al. showed that opioids are more effective than placebo for improving pain and helping patients to get back on track in their daily activities, regardless of the type of opioid used (weak or strong) or the pain mechanism (neuropathic or nociceptive). Furthermore, they found that improvement was greater for pain than for functionality [12]. 
Box 1. Evidence of efficacy of opioid use.

\section{Indicated}

- Osteoarthritis

- Rheumatoid arthritis

- Diabetic polyneuropathy

- Peripheral neuropathy

- Postherpetic neuralgia

- Phantom limb pain

- Lower back pain

- Lumbar radiculopathy

- After spinal cord compression

- After brain lesions (cerebrovascular neurological disease, thalamic, multiple sclerosis)

- Polyneuropathy by HIV, alcohol, chemotherapy and others

- Ischemia or occlusive arterial disease

- Secondary to pressure ulcers, stages III-IV

- Complex regional pain syndrome

- Chronic postsurgical pain

- Fibromyalgia (only with tramadol)

Not indicated

- Primary headache (migraine, headache, tension headache)

- Functional disorders (irritable bowel syndrome, post-traumatic stress disorder, chronic fatigue syndrome, restless legs syndrome)

- Severe affective disorder and/or suicidal tendency

- Use or abuse of illegal drugs, controlled drugs or doubts about the responsibility of the patient with opioid use

- Current, or planned pregnancy

- Precaution in:

- Untreated obstructive sleep apnea

- Chronic lung disease

- Heart condition; e.g., methodone-associated QT interval prolongation (QTc interval 450-500 ms) may increase the risk of potentially severe arrhythmias

- Paralytic ileus

- Suicide risk or unstable psychiatric disorder

Data taken from $[10,11]$.

\section{When do we need to consider starting opioid treatment?}

- Pain intensity becomes moderate to severe;

- Failure of nonopioid pharmacological therapy;

- Pain significantly impacts function and everyday activities. On the whole, it is considered that a patient is not improving when functional improvement is not higher than 20-30\%;

- Contraindications for NSAIDs use: allergy; active ulcers in the digestive tract or history of upper or lower digestive bleeding; elderly patients with comorbidities or receiving anticlotting drugs [13], patients with heart failure or hypertension (which is not under control) [14], patients with renal failure or liver disease (especially Child-Pugh class B and C).

\section{Informed consent}

All guidelines for the use of opioids in patients with CNOP should be evidence-based and clearly communicated. The process of communication between physician and patient should include $[10-11,15]$ :

- General information about diagnosis, medication and objective;

- Goals of treatment;

- Risks and benefits of treatment;

- Accurate recommendations about titration. 
Informed consent helps to improve physicianpatient rapport. It should be read and accepted by the patient at the start of opioid treatment. If a written consent form is not used, at the very least the treating physician should orally inform the patient about the treatment they are about to receive and what they might expect in terms of pain relief. This should be recorded on the patient's medical record [16].

\section{Management with opioids}

In order to determine the type of pain management, it is fundamental to [10]:

- Know the patient: age, diagnosis, prognosis, awareness, psychoemotional status, psychosocial background and history of substance abuse (alcohol, tobacco, benzodiazepines, opioids, drugs, addiction risk, among others);

- Determine the type of pain: nociceptive (somatic or visceral), neuropathic, or a combination of both;

- Evaluate pain intensity: mild, moderate and severe;

- Consider comorbidities, especially ones that may potentiate adverse effects or ones which cause polypharmacy and increase the risk of pharmacological interactions, as well as alter plasma levels of the opioid;

- Once these issues have been assessed, it is necessary to know which opioids are available:

- Weak opioids: tramadol, codeine and hydrocodone;

- Strong opioids: morphine, oxycodone, hydromorphone, methadone, fentanyl, buprenorphine and tapentadol.

All opioid analgesics act by binding mainly to $\mathrm{Mu}$ opioid receptors (MOR) located both presynaptically and postsynaptically in the pain nociceptive pathway [17]. Tapentadol is slightly different in that it acts as a MOR agonist and noradrenaline reuptake inhibitor. Both mechanisms of action have been shown to contribute to the analgesic activity of tapentadol and to produce analgesia in a synergistic manner, such that relatively moderate activity at the two target sites (MOR and noradrenaline reuptake transporter) is sufficient to produce strong analgesic effects [18].

After considering all of the above mentioned concepts, the selection of opioid, initial dose and titration should be individualized [11,19-20]
Physicians and patients should consider the initial treatment with opioids as a therapeutic test (4-8 weeks) to determine if this is the most suitable treatment for the individual's pain. Therapeutic benefits need to be evaluated in relation to potential risks [20].

Table 1 contains a proposed initial titration scheme, which may be modified according to the response, adverse events or type of planned monitoring. Titration should begin slowly and at low doses. In the case of elderly (geriatric) patients, doses should be decreased by $50 \%$; with shortacting opioids being preferred [20]. A rescue dose is recommended as being $10-20 \%$ of the total daily dose [10].

The titration phase ends when the optimal dose is reached or, on the contrary, when the therapeutic test is considered to have failed.

A test is considered a failure when the patient does not experience enough analgesia after increasing the dose two- to three-times, or when unacceptable adverse events or medical complications appear. Aberrant behavior of a patient after receiving medication is also regarded a therapeutic failure $[10,20]$.

After therapeutic failure, it is recommended that treatment with opioids is interrupted. However, treatment should never be abruptly interrupted; a period of progressive decrease is necessary (from 2-3 weeks up to 3-4 months). During that interval, the patient should be monitored closely. The dose reduction rate varies in every case and may vary from a daily reduction of $10 \%$ to a $10 \%$ reduction every $1-2$ weeks. If withdrawal symptoms appear or the intensity of pain increases at any step of the dose reduction process, it will be necessary to stop the dose reduction process (weaning) $[10,20]$.

In the case of concomitant use of opioids and benzodiazepines during the therapeutic test, it is recommended to consider decreasing them both at the same time: either by stopping their administration or by slow downward titration [10].

A careful analysis needs to be undertaken to decide whether opioid therapy is an option for patients with a history of: personal or family substance-abuse, childhood abuse or psychiatric comorbidity. If the plan is to start opioid treatment in a patient at high risk of substance abuse, it is recommended to implement it only for well-defined pain conditions. Treatment should be initiated with low doses, followed by slow upward titration, and with close monitoring for signs of aberrant behaviors associated with opioid 


\begin{tabular}{|c|c|c|c|}
\hline Opioid & Pain intensity & Starting dose & $\begin{array}{l}\text { Interval to } \\
\text { increase dose }\end{array}$ \\
\hline $\begin{array}{l}\text { Codeine alone or combined } \\
\text { with paracetamol/ibuprofen }\end{array}$ & Mild to moderate & $15-30 \mathrm{mg} / 6 \mathrm{~h}$ & 7 days \\
\hline $\begin{array}{l}\text { Tramadol + paracetamol } \\
(37.5 / 325 \mathrm{mg})\end{array}$ & Mild to moderate & 1 tablet $/ 4-6 \mathrm{~h}$ & 7 days \\
\hline Tramadol LP & Mild to moderate & $50-100 \mathrm{mg} / 12 \mathrm{~h}$ & $2-5$ days \\
\hline Morphine IR & Mild to moderate & $\begin{array}{l}5-10 \mathrm{mg} / 4-6 \mathrm{~h} \text {; maximum } \\
40 \mathrm{mg} / \text { day }\end{array}$ & 7 days \\
\hline Morphine retard & Mild to moderate & $\begin{array}{l}10-30 \mathrm{mg} / 1-3 \text {-times a day; } \\
\text { maximum } 40 \mathrm{mg} / \text { day }\end{array}$ & 14 days \\
\hline Oxycodone IR & Severe & $5 \mathrm{mg} / 4-6 \mathrm{~h}$; maximum $30 \mathrm{mg} /$ day & 7 days \\
\hline Oxycodone retard & Severe & $\begin{array}{l}10 \mathrm{mg} / 2 \text {-3-times a day; maximum } \\
30 \mathrm{mg} / \text { day }\end{array}$ & 14 days \\
\hline Hydromorphone IR & Severe & $1-2$ mg/4-6 h; maximum 8 mg/day & 7 days \\
\hline Hydromorphone retard & Severe & $\begin{array}{l}3 \mathrm{mg} / 2-3 \text { times a day; maximum } \\
9 \mathrm{mg} / \mathrm{day}\end{array}$ & 14 days \\
\hline Methadone & Severe & $2.5 \mathrm{mg} / 8 \mathrm{~h}$ & 7 days \\
\hline
\end{tabular}

use [10,20-21]. The incidence of the following aberrant behaviors should always be monitored:

- Treatment noncompliance or dose-skipping;

- Search for various simultaneous prescribers (shopping for doctors);

- Loss of prescriptions;

- Requests for prescriptions before scheduled time;

- Unscheduled visits to the doctor's office or the emergency department because of complaints related to lack of pain control;

- Patient's request for an increase in the opioid dose that is not clearly justifiable.

\section{Transdermal therapy}

Two opioid transdermal patches are available: fentanyl and buprenorphine. Both drugs are classified as strong opioids, but the new, lowdose transdermal buprenorphine may be used for moderate pain. It is advisable to wait at least a few days to observe the response to a patch before modifying the dose, and observe the same precautions as with any other methods of administration [15,22].

In general, transdermal therapy is useful because:

- due to this route of administration, opioids are only minimally stimulant;
- it may be useful when oral presentation is not possible;

- it may be useful if there is any degree of cognitive damage.

\section{Chronic opioid therapy}

Short-acting opioids are safer for initial therapy since they are associated with a lower risk of overdose during titration [10,23]. Subsequently, the use of sustained-release opioids is recommended at regular intervals $[10,23]$. Oral opioids are preferred over parenteral opioids due to easier administration [24].

Dose increases should be carried out gradually, always attempting to maintain a low dose and using, whenever possible, adjuvant analgesics. The combination of short-acting and longacting opioids is common as a base therapy for initial treatment, and as additional or rescue doses in secondary therapy $[10,23]$. The use of long-acting opioids in high doses should be carefully considered [10-12,15,19-20,25].

Patients with CNOP may be treated in an efficient manner with morphine doses (lower than 200 mg or its equivalent). Before surpassing this limit, it is recommended to re-evaluate the patient, confirm the diagnosis, find out if more studies are needed, and determine if a nonopioid therapy is available. In addition, the existence of an inadequately treated mental health issue should be excluded. Opioid rotation 
should also be considered in order to improve efficacy/tolerability [10,20,23,24].

When administering a new opioid in a patient with previous exposure (opioid rotation), it is important to calculate equi-analgesic doses (Table 2). This calculation makes use of clinical findings from studies comparing the relative potencies of each opioid, and since the evidence is sometimes weak, the data have limitations. That is why, no matter the table or system chosen, it is crucial to be mindful that the calculation is an estimation and the need for individual monitoring and titration remains $[26,27]$.

For safety reasons, after calculation of the equi-analgesic dose, it is always recommended to make a $25-50 \%$ reduction in the calculated dose. As a rule, the preferred reduction is $30 \%$. No calculation, as good as the method used may be, replaces clinical criteria and experience [26,27].

The rescue dose or as-needed dose (PRN) should not be prescribed long-term, unless pain is intermittent and short-lasting, or the intensity of pain varies significantly during the afternoon.

It is critical to know the right time to refer the patient to a specialist $[24,28]$ :

- If there is no improvement in pain control after three consecutive dose escalations;

- If pain is not alleviated in patients with no history of opioid use with doses between 90 and $120 \mathrm{mg} /$ day of morphine or its equivalent;

- If an additional increase of $50 \%$ of the dose does not achieve pain relief;

- If aberrant behavior occurs.

The patient should reach a level of pain relief that improves functional ability. The adequate dose is one that alleviates pain in the patient and does not cause adverse events which impair functionality and/or quality of life.

\begin{tabular}{|c|c|c|}
\hline \multirow[t]{2}{*}{ Drug } & \multicolumn{2}{|c|}{ Equi-analgesic doses } \\
\hline & Parenteral & Oral \\
\hline Morphine & $10 \mathrm{mg}$ & $20 \mathrm{mg}$ \\
\hline Buprenorphine & $0.3 \mathrm{mg}$ & $0.4 \mathrm{mg}$ (sublingual) \\
\hline Codeine & $100 \mathrm{mg}$ & $200 \mathrm{mg}$ \\
\hline Fentanyl & $0.1 \mathrm{mg}$ & NA \\
\hline Hydromorphone & $1.5 \mathrm{mg}$ & $7.5 \mathrm{mg}$ \\
\hline Oxycodone & $10 \mathrm{mg}$ & $20 \mathrm{mg}$ \\
\hline Tramadol & $100 \mathrm{mg}$ & $120 \mathrm{mg}$ \\
\hline
\end{tabular}

Monitoring

Regular monitoring of patients with chronic opioid use is essential to identify treatmentadherence problems including underuse, overuse or misuse. A comprehensive evaluation should investigate compliance with treatment/dosage and the level of pain control/functional ability for each individual [29]. Long-term opioid therapy must be monitored for analgesic efficacy, adverse events, improvement in functionality, medical complications and aberrant behavior [15].

It is recommended to use different tools to help the patient maintain pain control and avoid adverse events including:

- Only one physician/pain team responsible for evaluating and reevaluating a patient according to circumstances [20,30];

- Taking a medical history; evaluating medical and psychological diagnoses; recording pain intensity, functional level, presence of adverse events, adherence to treatment and the complete prescription scheme [15,20,23-24,30];

- Obtain informed consent [10,15,20,23-24];

- Use the same pharmacy to obtain medicines, if possible;

- Education in the use of opioids for doctors, providers and patients is crucial [15,20,23-24];

- Psychoeducation for the family in order to inform them about possible adverse effects and aberrant behaviors;

- Patients at high-risk or with a history of drug abuse must undergo periodic urine drug testing along with regular checks of their prescribed opioid (tablet/capsule counts). The patient should be notified one day before control consultation or on the same day. An incorrect count indicates inappropriate use of medication $[15,20,30]$;

- While all patients should be monitored on an on-going basis, for patients at high-risk or in need of frequent surveillance, the monitoring should be carried out weekly (Box 2) [20] .

Problems with long-term opioid treatment

\section{- Adverse events}

Around $80 \%$ of patients who begin an opioid treatment experience one or more adverse events such as nausea, vomiting, constipation, sleepiness, dizziness, vertigo, itching and cognitive impairment. 
Tolerance to these events can occur when stable doses are reached. The majority of adverse events are uncommon, with the exception of constipation, which should always be prevented or treated with laxatives (depending on the case), or rectal interventions (enemas and suppositories if needed) which are usually used when there is no evacuation for more than 3 days [31]. Drugs such as naloxone, methylnaltrexone, alvimopan and opioid receptor antagonists also have positive effects on this condition. Opioid switching is a very common practice in such patients, especially trying transdermal formulations because they have less risk of causing constipation and the use of laxatives decreases [32].

Medical complications comprise neuroendocrine abnormalities, erectile dysfunction, hyperalgesia induced by opioids [23,30], and immunosuppression. This occurs more often with pure agonists such as morphine and is lower with opioids such as tramadol and buprenorphine [23,33,34].

\section{- Addiction}

Different publications indicate that the risk of patients with CNOP developing addiction is variable. Although it is not clear what the trigger factors are, addiction may be influenced by social and psychological factors (anxiety, poor self-esteem), history of alcohol or benzodiazepine abuse, and personality disorders $[35,36]$. Regular monitoring is mandatory in patients with complex psychiatric diseases who may require rapid dose increases, and in patients with opioid-induced hyperalgesia [23].

\section{- Treatment withdrawal}

The main reasons why patients abandon treatment are adverse events (17.5-32.5\%) and poor efficacy $[23,37]$.

- Public policies to warrant access to opioids One of the main issues in Latin America with respect to opioid use is their limited availability, as well as the standardization of adequate treatment for moderate to severe pain. At the request of the World Health Assembly and the Economic and Social Council of the United Nations [38], in 2012 the WHO created the Access to Controlled Medications Program which had several aims: to guide international regulations which will govern these medications; to analyze policies and legislation in order to define strategies that improve access; and to train governments and health personnel [39].
Box 2. Recommendations for appropriate monitoring interval.

Low risk of adverse effects and with stable doses of opioids

- Monitoring at least once every 3-6 months

High risk for adverse effects ${ }^{\dagger}$

- More efficient or intense control, at least in the initial period after treatment inititation or changes in opioid doses

\section{Very high risk for adverse effects}

\section{- Weekly monitoring}

${ }^{\dagger}$ Patients with addiction background, elderly, patients with cognitive impairment, emotional instability or psychiatric comorbidities [20].

Despite such international policies, the inequality to access of adequate analgesia is the same around the world. Institutional, medical and patient barriers hinder the appropriate management of pain with opioid therapy; largely because of a lack of information and/or education [40].

In the context of this article, Latin America is considered to be one of several regions with limited access to opioids, especially when compared with North America and Europe [41,42]. Nowadays, policies about the distribution and prescription of opioids are different in each LatinAmerican country and these differences significantly influence availability. Since regulations are rather restrictive, opioid shortage is evident across the region, but particularly in Central America. In addition, there are other restrictions to opioid availability, including economic factors [43].

Many Latin-American countries do not meet the minimum indicators of opioid availability for the population which requires it. Furthermore, the process for obtaining adequate availability of strong medications for pain management in Latin-American countries appears to be difficult, not only because of poor training of healthcare personnel in general, but also as a result of poor distribution of the appropriate medication for pain control.

\section{Conclusion}

The objectives of treatment for $\mathrm{CNOP}$ are based not only on pain relief, but also on improving the functioning and quality of life of the patient. Consequently, the physician must take into consideration the balance between risks and benefits when prescribing opioids, because this represents one of the keys to successful treatment. How can we succeed in this? There is no unfailing formula, but, fortunately, clinical practice and scientific evidence have enabled the establishment of steps to help us make the best therapeutic decision, always based on the risk/benefit balance. In Latin America, there are problems such 
as limited availability and accessibility to opioids; fear of the rational use of opioids, and a lack of education in pre and postgraduate medical education. Therefore, it is imperative to develop and communicate clear guidelines, adapted to the Latin-American reality, in order to contribute to the improvement of the quality of life of patients with CNOP.

Potential limitations of the study relate to the heterogeneity of the treatment population. This heterogeneity is based not only on pharmacogenomics (which influences clinical response), but also on the different accessibility to opioids among the various Latin American regions. Application of these guidelines is thus influenced by these factors.

\section{Acknowledgements}

The authors would like to thank Grünenthal Latin America for its unrestricted support in the logistics for our meeting to take place.

\section{Financial \& competing interests disclosure}

Grünenthal Services, Inc. provided logistic support for the experts to be gathered. The authors have no other relevant affiliations or financial involvement with any organization or entity with a financial interest in or financial conflict with the subject matter or materials discussed in the manuscript apart from those disclosed.

Editorial assistance was provided by Content Ed Net (Madrid, Spain) and supported by Grünenthal Services, Inc.

\section{References}

Papers of special note have been highlighted as:

- of interest

1 Cousins MJ, Lynch ME. The Declaration Montreal: access to pain management is a fundamental human right. Pain 152, 2673-2674 (2011).

- This publication was a milestone in the history of contemporary medicine, as it established that pain relief was an important unmet need, as well as human right, a concept endorsed by highly relevant institutions, such as WHO, International Association for the Study of Pain and European Pain Federation.

2 Brennan F, Carr DB, Cousins M. Pain management: a fundamental human right. Anesth. Analg. 105, 205-221 (2007).

3 Treede R, Rief W, Barke A et al. A classification of chronic pain for ICD-11. Pain 156, 1003-1007 (2015).

4 Henschke N, Kamper S, Maher Ch. The epidemiology and economic consequences of pain. Mayo Clin. Proc. 90, 139-147 (2015).

5 Garcia JBS. Change Pain Latin America -new initiative established to enhance management of patients with chronic pain in Latin America. Rev. Bras. Anestesiol. 64, 140-142 (2014).

- A group of opinion leaders, who are also renowned specialists in pain management, have developed an initiative called Change Pain aimed at improving pain management in Latin-American patients through education, research, and diffusion of best practices.

6 Wynne-Jones G, Vande Windt D, Ong BN et al. Perceptions of health professionals towards the management of back pain in the context of work: a qualitative study. $B M C$ Musculoskelet. Disord. 15, 210 (2014).
7 Cicad Plan Nacional de Prevención Integral de Drogas. 2012-2013.

www.cicad.oas.org

8 Lohman D, Schleifer R, Amon J. Access to pain treatment as a human right. BMC Med. 8, 8 (2010).

9 Rico M, Kraychete C, Iskandar J et al. Use of opioids in Latin America: the need of an evidence-based change. Pain Med. 17, 704-716 (2016).

- Recent publication by Change Pain Latin-American group, in which the need to change clinical practices on the use of opioids is established on the basis of the best evidence available.

10 Kahan M, Mailis-Gagnon A, Wilson L, Srivastava A; National Opioid Use Guideline Group. Canadian guideline for safe and effective use of opioids for chronic noncancer pain: clinical summary for family physicians. Part 1: general population. Can. Fam. Physician 57, 1257-1266 (2011).

- One of the first and more complete guidelines aimed at promoting rational and safe prescription of opioids for noncancer pain, and which set the scene for further publications on this topic.

11 Häuser W, Bock F, Engeser P, Tölle T, Willweber-Strumpfe A, Petzke F. Clinical practice guideline: Long-term opioid use in non-cancer pain. Dtsch Arztebl. Int. 111, 732-740 (2014).

12 Kalso E, Edwards JE, Moore RA, McQuay HJ. Opioids in chronic non-cancer pain: systematic review of efficacy and safety. Pain 112, 372-380 (2004).

13 O’Neil Ch, Hanlon J, Marcum ZA. Adverse effects of analgesics commonly used by older adults with osteoarthritis: focus on non- opioid and opioid analgesics. Am. J. Geriatr. Pharmacother. 10(6), 331-342 (2012).

14 Singh BK, Haque SE, Pillai KK. Assessment of nonsteroidal anti-inflammatory druginduced cardiotoxicity. Expert Opin. Drug Metab. Toxicol. 10, 143-156 (2014).

15 Trescot A, Helm S, Hansen $\mathrm{H}$ et al. Opioids in the management of chronic non cancer pain: an update of American Society of the Interventional Pain Physicians' (ASIPP) Guidelines. Pain Physician 11, S5-S62 (2008).

16 Cheatle MD, Savage SR. Informed consent in opioid therapy: a potential obligation and opportunity. J. Pain Symptom Manage. 44(1), 105-116 (2012).

17 Bruera E, Paice JA. Cancer pain management: safe and effective use of opioids. Am. Soc. Clin. Oncol. Educ. Book 2015, e593-e599 (2015).

18 Tzschentke TM, Christoph T, Kögel BY. The mu-opioid receptor agonist/noradrenaline reuptake inhibition (MOR-NRI) concept in analgesia: the case of tapentadol. CNS Drugs 28(4), 319-29 (2014).

19 Cheung CH, Qui Q, Choi SW, Moore B, Goucke R, Irwin M. Chronic opioid therapy for chronic non cancer pain: a review and comparison of treatment guidelines. Pain Phys. 17, 401-414 (2014).

20 Chou R, Fanciullo GJ, Fine PG et al. Clinical guidelines for use of chronic opioid therapy in chronic noncancer pain. J. Pain 10, 113-130 (2009).

21 Passik SD, Squire P. Current risk assessment and management paradigms: snapshots in the life of the pain specialist. Pain Med. 10(Suppl. 2), S101-S114 (2009).

22 Khanna IK, Pillariserri S. Buprenorphine -an attractive opioid with underutilized potential 
in treatment of chronic pain. J. Pain Res. 4, 859-870 (2015).

23 VA/DoD Opioid Therapy for Chronic Pain Working Group. (2010). The management of opioid therapy for chronic pain. www.healthquality.va.gov

24 Ho KY, Chua NH, George JM et al. Evidence-based guidelines on the use of opioids in chronic non-cancer pain-a consensus statement by the Pain Association of Singapore Task Force. Ann. Acad. Med. Singapore 42(3), 138-152 (2013).

25 Manchikanti L, Abdi S, Atluri S et al. American Society of Interventional Pain Physicians (ASIPP) guidelines for responsible opioid prescribing in chronic non-cancer pain: part 2-guidance. Pain Physician 15(3), S67-S116 (2012).

- A publication in which interventional experts in the field of pain management put forward their perspective on the responsible use of opioids in chronic noncancer pain.

26 Webster L, Fine PG. Review and critique of opioid rotation practices and associated risks of toxicity. Pain Med. 13, 562-570 (2012).

- A review of the methods for opioid rotation, their utility and associated risks.

27 McPherson ML. Desmistifying opioid conversion calculations. American Society of Health System USA (2009). www.ashp.org

28 Deyo RA, Von Korff M, Duhrkoop D. Opioids for low back pain. BMJ 350, g6830 (2015).

29 Gordon DB, Dahl JL, Miaskowski C et al. American Pain Society recommendations for improving the quality of acute and cancer pain management. American Pain Society Quality of Care Task Force. Arch. Intern. Med. 165, 1574-1580 (2005).

30 Canadian Guideline for Safe and Effective Use of Opioids for Chronic Non-Cancer Pain 2010 National Opioid Use Guideline Group (NOUGG).

http://nationalpaincentre.mcmaster.ca
31 Labianca R, Sarzi-Puttini P, Zuccaro SM, Cherubino P, Vellucci R, Fornasari D. Adverse effects associated with non-opioid and opioid treatment in patients with chronic pain. Clin. Drug Investig. 32(1), 53-63 (2012).

- Review of side effects of commonly used drugs in patients with chronic pain, including a critical appraisal of the analgesic groups most frequently prescribed for this condition, along with their potential effects, prevention and management. Previous comorbidity is also considered.

32 Díaz P, Tamayo A. Efectos gastrointestinales. In: Uso de opioides en Tratamiento del Dolor. Manual para Latinoamérica. Bonilla P, De Lima L, Díaz P, León MX, González M (Eds). TIPS Imagen y Comunicación 1967 CA, Caracas, Venezuela, 100-113 (2011).

33 Al-Hashimi M, Scott SW, Thompson JP, Lambert DG. Opioids and immune modulation: more questions than answers. $\mathrm{Br}$. J. Anaesth. 111, 80-88 (2013).

34 Garcia JB, Cardoso MGM, Dos-Santos MC. Opioids and the immune system: clinical relevance. Rev. Bras. Anaestesiol. 62(5), 709-718 (2012).

35 Pain and substance misuse: improving the patient experience. A consensus statement prepared by The British Pain Society in collaboration with The Royal College of Psychiatrists, The Royal College of General Practitioners and The Advisory Council on the Misuse of Drug. The British Pain Society, 2010.

www.britishpainsociety.org

36 Juurlink DN, Dhalla IA. Dependence and addiction during chronic opioid therapy. J. Med. Toxicol. 8(4), 393-399 (2012).

37 Noble M, Tregear SJ, Treadwell JR, Schoelles K. Long-term opioid therapy for chronic noncancer pain: a systematic review and meta-analysis of efficacy and safety. J. Pain Symptom Manage. 35, 214-228 (2008).

38 United Nations Economic and Social Council (ECOSOC). Resolution 2005/25. Treatment of pain using opioid analgesics.

www.un.org

39 Acceso y uso racional de los medicamentos Departamento de Medicamentos Esenciales y Políticas Farmacéuticas Sistemas y servicios de salud, Organización Mundial de la Salud. www.who.int

- This highly relevant article establishes that the program on the access to controlled drugs represents the first and only worldwide initiative in this field. National mechanisms are assessed by providing scientifically based guidelines, policy analyses, qualification and practical help measures in an attempt to furnish national governments with universal, worldwide-recognized norms on the clinical use of controlled drugs.

40 Duthey B, Scholten W. Adequacy of opioid analgesic consumption at country, global, and regional levels in 2010, its relationship with development level, and changes compared with 2006. J. Pain Symptom Manage. 47, 283-297 (2014).

- A publication that advocates the use of Adequacy of Opioid Analgesic Consumption to define needs at country, region and global levels, as well as changes introduced between 2006 and 2010.

41 International Narcotics Control Board: WHO population data by: pain \& policy studies group. University of Wisconsin/ WHO collaboration center (2014). http://www.painpolicy.wisc.edu/

42 Lamas D, Rosenbaum L. Painful inequities - palliative care in developing countries. N. Engl. J. Med. 366, 199-201 (2012).

43 Ryan K, De Lima L, Maurer M. Disponibilidad acceso y políticas sanitaria en medicamentos opioides en latinoamérica. In: Uso de opioides en Tratamiento del Dolor. Manual para Latinoamérica. Bonilla P, De Lima L, Díaz P, León MX, González M (Eds). IAHPC Press, Caracas, Venezuela, 20-41 (2011). 